\title{
Effect of Calcination Conditions on the Performance of Co-precipitation Catalyst
}

\author{
Kai $\operatorname{LIN}^{1, \mathrm{a}}$, Wensong $\mathrm{CHEN}^{1, \mathrm{~b},{ }^{*}}$, Yongli $\mathrm{ZHANG}^{2, \mathrm{c}}$ and Junjian $\mathrm{XU}^{2, \mathrm{~d}}$ \\ ${ }^{1}$ Faculty of Environmental Science and Engineering, Guangdong University of Technology, \\ Guangzhou 510006, China \\ ${ }^{2}$ School of Chemical and Environmental Engineering, Hanshan Normal University, Chaozhou 521041, \\ China \\ akai306301@163.com, ${ }^{\mathrm{b}} 670511263 @ q q . c o m,{ }^{c} \mathrm{zyl} \_12382 @ 163 . c o m,{ }^{\mathrm{d}}$ soldy@126.com
}

\begin{abstract}
The Fe-Co-Ce composite catalysts were prepared by co-precipitation method, and the effect of calcination temperature and calcination time on the performances of the Fe-Co-Ce composite catalysts were investigated. The results indicated that the optimum calcination temperature and calcination time of the $\mathrm{Fe}-\mathrm{Co}-\mathrm{Ce}$ composite catalysts were $450{ }^{\circ} \mathrm{C}$ and $7 \mathrm{~h}$, respectively. Using the catalysts which prepared under the optimum calcination conditions catalytic wet oxidation of methyl orange simulated wastewater, after $90 \mathrm{~min}$, the COD, COD removal rate, absorbance, decolorization rate and $\mathrm{pH}$ of the methyl orange simulated wastewater were $737.7,70.5 \%, 0.348,95.3 \%$, and 5.31 , respectively. According to the analyses of the SEM, FTIR, and TG-DTA curves, the components of the catalysts which prepared under the optimum calcination conditions distributed evenly, and the chemical compositions of the catalysts including $\mathrm{C}-\mathrm{O},-\mathrm{OH}$, and $\mathrm{H}-\mathrm{O}-\mathrm{H}$, showing a good thermal stability.
\end{abstract}

\section{Introduction}

With the rapid development of industry, environmental pollution has become a huge problem for human survival and development. There are a lot of wastewaters discharged from printing and dyeing plants every day, and it is difficult to dispose the organic industrial wastewaters, because they are usually composed of high-concentration of refractory biochemical organic pollutants, ammonia nitrogen compounds, and suspended matters or other pollutants, which cause a serious pollution for the natural water [1]. At present, the main treatment methods of the complex and refractory wastewater are ozonation method [2], biological degradation method [3], and electrolysis method [4], however, the traditional biological or physical chemical purification methods are difficult to satisfy the requirements of the purification treatment technology and economy [5]. In order to treat the industrial

* Corresponding author:670511263@qq.com 
wastewater more appropriately, it is necessary to seek a treatment method with economic rationality, harmless, reduction and recycling.

Compared with the conventional treatment method, catalytic wet oxidation is widely used in wastewater treatment due to the advantages of wide application range, quick oxidation rate and less secondary pollution, less energy consumption. The transition metal can effectively improve the catalytic performance of noble metal catalysts, due to the synergistic effect between transition metal and noble metal [7]. Therefore, using transition metal modified metal catalyst has become a hot research topic. The calcination temperature and calcination time of the Fe-Co-Ce composite catalysts have a significant impact for the performance of catalytic wet oxidation, so it is necessary to find the optimum calcination conditions of the catalysts before catalytic wet air oxidation of wastewater.

The Fe-Co-Ce composite catalysts were prepared by co-precipitation method, investigating the effect of calcination temperature and calcination time on the performance of catalytic wet air oxidation, and the structure and thermal stability of the catalysts were determined by SEM, FTIR, and TG-DTA.

\section{Materials and Methods}

\subsection{Samples and Materials}

The wastewater used in the experiment was the homemade methyl orange simulated wastewater. The parameters of simulated wastewater were shown in Table.1.

Table 1 Parameters Of Methyl Orange Simulated Wastewater

\begin{tabular}{|c|c|c|c|}
\hline $\begin{array}{c}\text { Concentration of methyl } \\
\text { orange }(\mathrm{mg} / \mathrm{L})\end{array}$ & CODcr $(\mathrm{mg} / \mathrm{L})$ & Absorbance & $\mathrm{pH}$ \\
\hline 1427.4 & 2500.8 & 7.740 & 6.78 \\
\hline
\end{tabular}

\subsection{Experimental}

The Fe-Co-Ce composite catalysts were prepared by co-precipitation method with the molar ratio for metal atoms of 1:1:1, and calcined in different calcination temperatures and times. Adding $250 \mathrm{~mL}$ methyl orange simulated wastewater and $0.5 \mathrm{~g} \mathrm{Fe}-\mathrm{Co}-\mathrm{Ce}$ composite catalyst after calcination into the high pressure reaction vessel, and reacted under the condition of $180{ }^{\circ} \mathrm{C}$ reaction temperature, $2.5 \mathrm{MPa}$ oxygen partial pressure, and $500 \mathrm{r} / \mathrm{min}$ rotate speed of the stirring device, $20 \mathrm{~mL}$ water samples were obtained in 10, 20, 40, 60 and 90 min respectively, which used for detection.

\subsection{Analysis Method}

The chemical oxygen demand $\left(\mathrm{COD}_{\mathrm{Cr}}\right)$ was determined according potassium dichromate method of National Standard (China GB11914-89). The absorbance was determined by using Gravimetric method. The chroma was determined by using dilution multiple methods. The $\mathrm{pH}$ was determined according glass electrode method. 


\section{Results and Discussion}

\subsection{Effects of Calcination Temperature on the Performance of Catalyst}

The Fe-Co-Ce composite catalysts were calcined at $300{ }^{\circ} \mathrm{C}, 450{ }^{\circ} \mathrm{C}, 600{ }^{\circ} \mathrm{C}$, and $750{ }^{\circ} \mathrm{C}$ for $3 \mathrm{~h}$, respectively. The effects of calcination temperature on the performance of the catalysts were shown in Fig.1. With the increase of the calcination temperature, the COD and absorbance of the methyl orange simulated wastewater were decreased gradually, while the COD removal rate and decolorization rate increased gradually. The $\mathrm{pH}$ of the methyl orange simulated wastewater gradually decreased, reached the lowest value when the sampling time was $60 \mathrm{~min}$, and then gradually rose. The catalytic performances of the catalysts decreased with the increase of the calcination temperature, but it was not obvious. The crystallizations of the catalysts which calcined at $300^{\circ} \mathrm{C}$ were not complete and the stability was poor. Therefore, the optimum calcination temperature of the catalysts was $450{ }^{\circ} \mathrm{C}$.
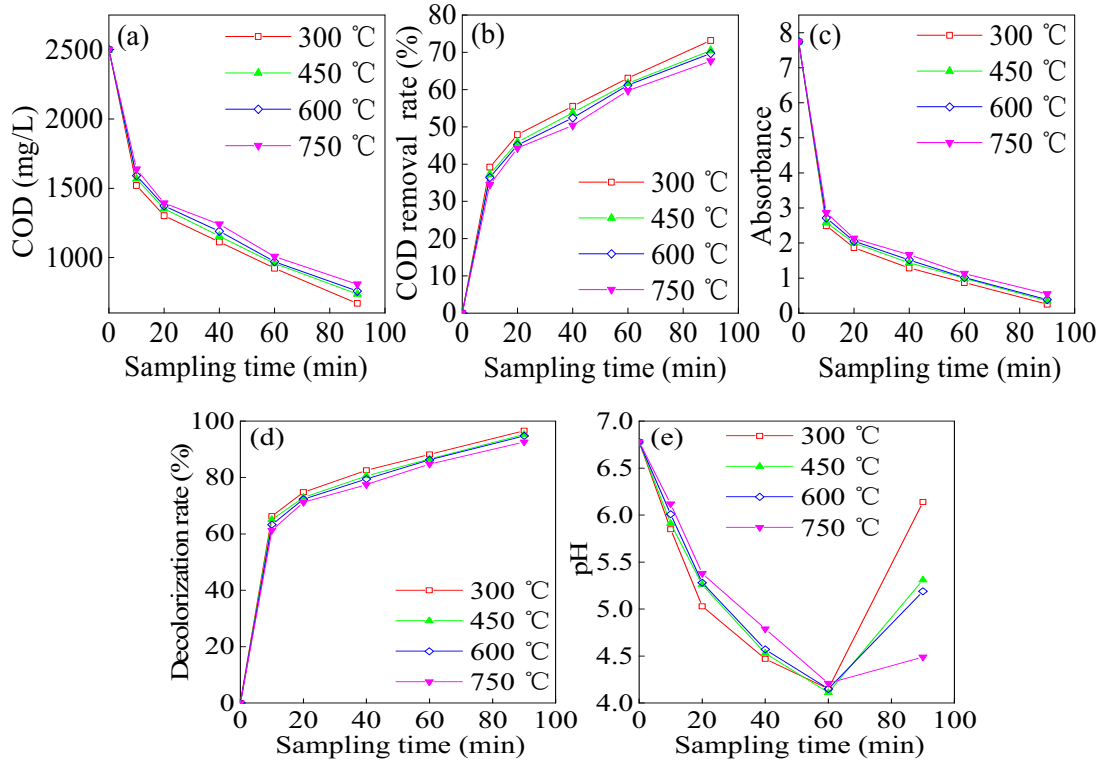

Fig. 1 Effect of calcination temperature on the performance of catalyst

\subsection{Effects of Calcination Time on the Performance of Catalyst}

The Fe-Co-Ce composite catalysts were calcined at $450{ }^{\circ} \mathrm{C}$ for $1 \mathrm{~h}, 3 \mathrm{~h}, 5 \mathrm{~h}$, and $7 \mathrm{~h}$, respectively. The effects of calcination time on the performance of the catalysts were shown in Fig.2. With the increase of the calcination time, the COD and absorbance of the methyl orange simulated wastewater were decreased gradually, while the COD removal rate and decolorization rate increased gradually. The $\mathrm{pH}$ of the methyl orange simulated wastewater gradually decreased, reached the lowest value when the sampling time was $60 \mathrm{~min}$, and then gradually rose. The catalytic performances of the catalysts decreased with the increase of the calcination time, but it was not obvious. The crystallizations of the catalysts which calcined for $1 \mathrm{~h}$ were not complete and the stability was poor. Therefore, the optimum calcination time of the catalysts was $3 \mathrm{~h}$. The COD, COD removal rate, absorbance, decolorization rate and $\mathrm{pH}$ were $737.7,70.5 \%, 0.348,95.3 \%$, and 5.31 , respectively after catalytic wet-air oxidation 
of methyl orange simulated wastewater for 90 min over the Fe-Co-Ce composite catalysts, and the catalysts were prepared under the condition that the calcination temperature and calcination time were $450^{\circ} \mathrm{C}$ and $3 \mathrm{~h}$, respectively.

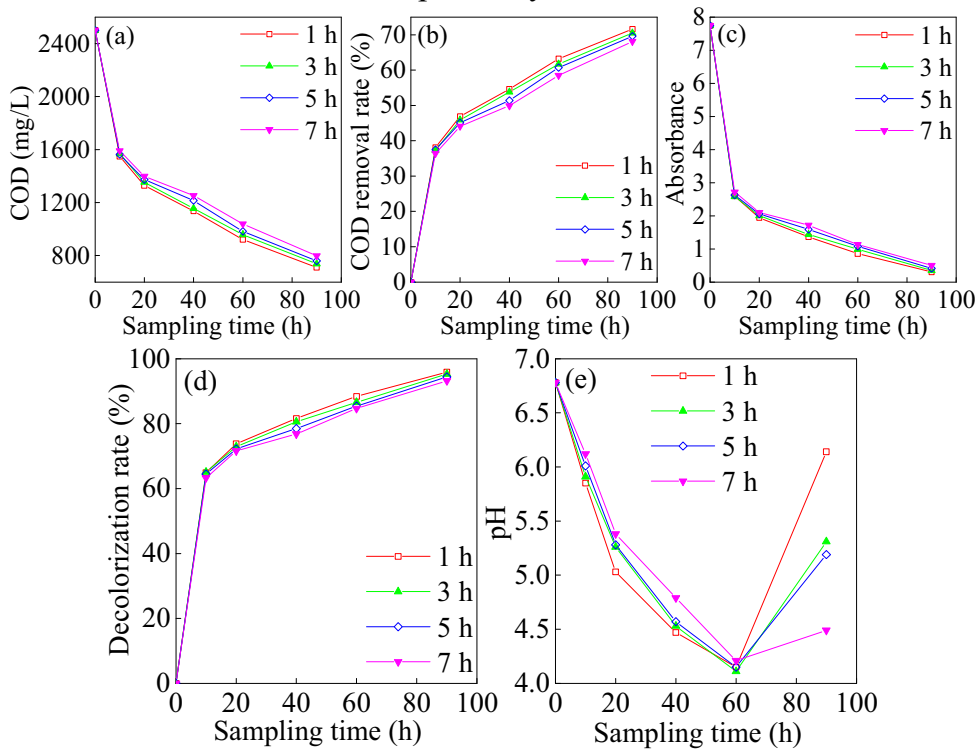

Fig. 2 Effect of calcination time on the performance of catalyst

\subsection{SEM Analysis}

The surface morphologies of the samples were observed by scanning electron microscopy (SEM), and the SEM images of the Fe-Co-Ce composite catalysts which prepared at $450{ }^{\circ} \mathrm{C}$ were shown in Fig.3. The components of the Fe-Co-Ce composite catalysts distributed evenly, which was conducive to improve the stability of the catalysts.
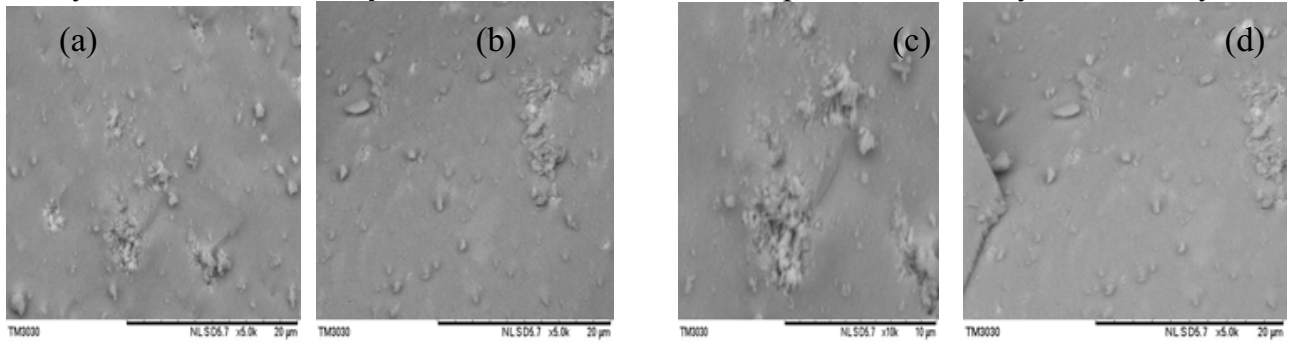

Fig.3 Scanning electron microscope images of the catalyst

\subsection{FTIR Analysis}

The FTIR spectra of the Fe-Co-Ce composite catalysts prepared at $300{ }^{\circ} \mathrm{C}, 450{ }^{\circ} \mathrm{C}$, $600{ }^{\circ} \mathrm{C}$, and $750{ }^{\circ} \mathrm{C}$ were shown in Fig. 4 (a-d). The characteristic peaks were assigned as follows: the bands at $808 \mathrm{~cm}^{-1}$ can be associated with the stretching vibrations of $\mathrm{C}-\mathrm{O}$, while the bands at $1400 \mathrm{~cm}^{-1}$ were ascribed to the stretching vibration absorption spectra of -OH. And the stretching vibration absorption spectra of $-\mathrm{OH}$ for the catalysts calcined at $450{ }^{\circ} \mathrm{C}$ was weak, which was related to the bending vibrations between $\mathrm{H}-\mathrm{O}-\mathrm{H}$ bonds of the catalysts. 

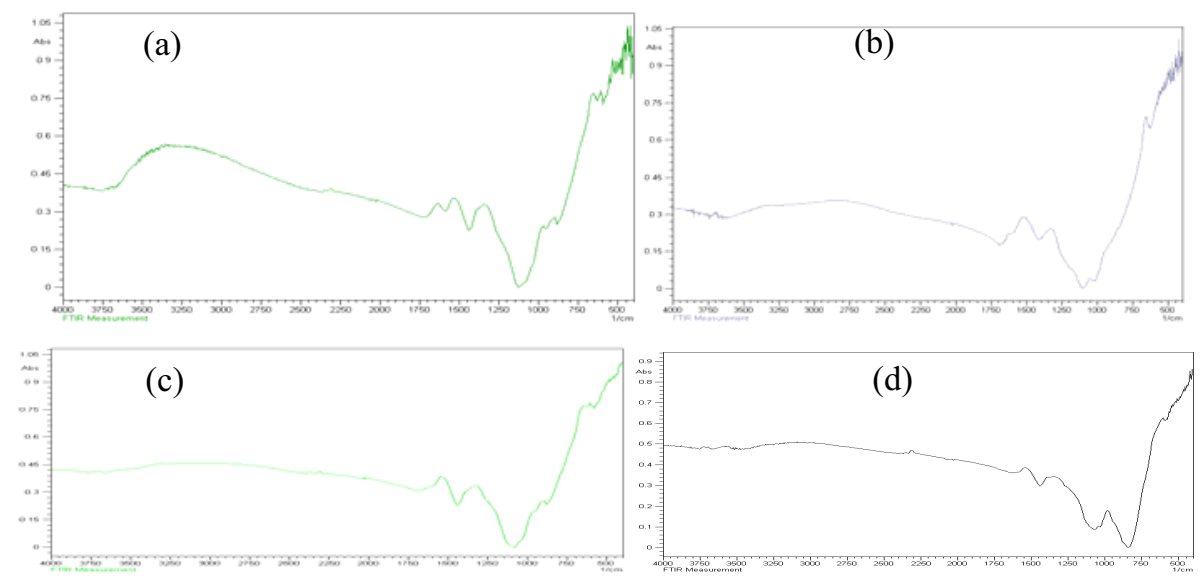

Fig. 4 FTIR spectra of catalysts prepared at different calcination temperatures

(a) $300{ }^{\circ} \mathrm{C}$; (b) $450{ }^{\circ} \mathrm{C}$; (c) $600{ }^{\circ} \mathrm{C}$; (d) $750{ }^{\circ} \mathrm{C}$

\subsection{TG-DTA Analysis}

The TG-DTA curves of the Fe-Co-Ce composite catalysts before calcination were shown in Fig.5 (a), and the amount of usage was $15.4 \mathrm{mg}$, while the TG-DTA curves of the Fe-Co-Ce composite catalysts after calcination were shown in Fig.5 (b), and the amount of usage was $16.6 \mathrm{mg}$. From Fig.5 (a), the weight loss of the catalyst was divided into three stages. The DTG curve has an endothermic peak in $93.6{ }^{\circ} \mathrm{C}$, corresponding to the range of 92-175.5 ${ }^{\circ} \mathrm{C}$ in the TG curve, and the sample weight loss was $4.4 \%$, which ascribed to the loss of adsorbed water. The DTG curve has a large endothermic peak in $180.3{ }^{\circ} \mathrm{C}$, corresponding to the range of $175.5-193.5^{\circ} \mathrm{C}$ in the TG curve, and the sample weight loss was $47.2 \%$, which may caused by the decomposition of the Fe-Co-Ce composite catalysts. The DTG curve has a small endothermic peak in $212.9^{\circ} \mathrm{C}$, corresponding to the range of 193.5-73.2 ${ }^{\circ} \mathrm{C}$ in the TG curve, and the sample weight loss was $5.3 \%$, which may caused by the damage of skeleton due to the high-temperature calcination of the catalyst materials. As shown in Fig.5 (b), the endothermic peaks were relatively small, which showed that the catalysts were stable after calcination.

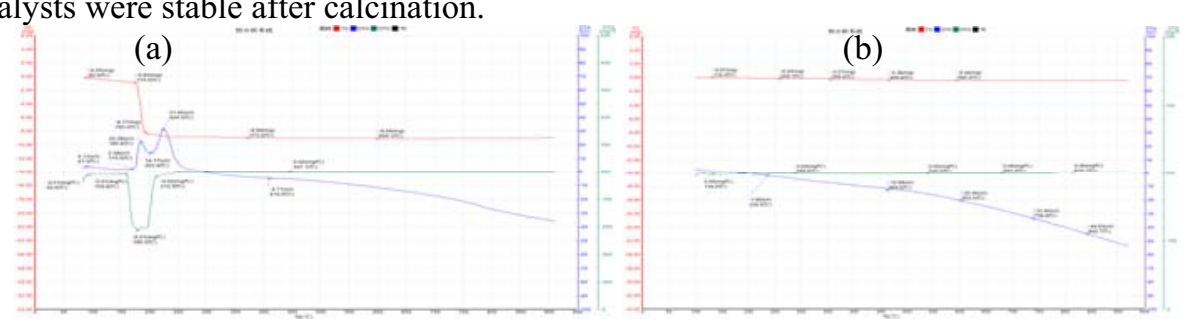

Fig. 5 TG-DTA curves of the catalyst

(a) Before roasting; (b) After roasting

\section{Conclusions}

(1) The optimum calcination temperature and calcination time of the $\mathrm{Fe}-\mathrm{Co}-\mathrm{Ce}$ composite catalysts were $450{ }^{\circ} \mathrm{C}$ and $7 \mathrm{~h}$, respectively.

(2) Using the Fe-Co-Ce composite catalysts which prepared under the optimum calcination conditions catalytic wet oxidation of methyl orange simulated wastewater, after 
90 min, the COD, COD removal rate, absorbance, decolorization rate and $\mathrm{pH}$ of the wastewater were $737.7,70.5 \%, 0.348,95.3 \%$, and 5.31, respectively.

(3) According to the analyses of the SEM, FTIR, and TG-DTA curves, the components of the $\mathrm{Fe}-\mathrm{Co}-\mathrm{Ce}$ composite catalysts which prepared under the optimum calcination conditions distributed evenly, and the chemical compositions of the catalysts including $\mathrm{C}-\mathrm{O},-\mathrm{OH}$, and $\mathrm{H}-\mathrm{O}-\mathrm{H}$, showing a good thermal stability.

\section{Acknowledgments}

This work was supported by the college professor starting project in Hanshan Normal University (QD20140615).

\section{References}

1. S X Yanga, M Bessonb, C Descorme. Catalytic Wet Air Oxidation of Succinic Acid over $\mathrm{Ru}$ and $\mathrm{Pt}$ Catalysts Supported on $\mathrm{Ce}_{\mathrm{x}} \mathrm{Zr}_{1^{-} \mathrm{x}} \mathrm{O}_{2}$ mixed oxides, Appl Catal B: Environ. 165 (2015) 1-9.

2. L A Bernal-Martíneza, C Barrera-Díaza, C Solís-Morelos, et al. Synergy of Electrochemical and Ozonation Processes in Industrial Wastewater Treatment, Chem Eng J. 165 (2010) 71-77.

3. R A Pereiraa, M F R Pereirab, M M Alves, et al. Carbon Based Materials as Novel Redox Mediators for Dye Wastewater Biodegradation, Appl Catal B: Environ. 144 (2014) 713-720.

4. F G Edwards, D Fendley, J V Lunsford. Electrolytic Treatment of an Industrial Wastewater from a Hosiery Plant, Water Environ Res. 78 (2006) 435-441.

5. E Skrzyńska, S Zaidb, J S Girardon, et al. Metals in the Crude Glycerol Oxidation, Appl Catal A: Gene. 499 (2015) 89-100.

6. S Maddila, S Rana, R Pagadala, et al. Synthesis of Pyrazole-4-carbonitrile Derivatives in Aqueous Media with $\mathrm{CuO} / \mathrm{ZrO}_{2}$ as Recyclable Catalyst, Catal Commun. 61 (2015) 26-30.

7. Z X Yan, M M Zhang, J M Xie, et al. A Bimetallic Carbide $\mathrm{Fe}_{2} \mathrm{MoC}$ Promoted Pd Electrocatalyst with Performance Superior to $\mathrm{Pt} / \mathrm{C}$ towards the Oxygen Reduction Reaction in Acidic Media, Appl Catal B: Environ. 165 (2015) 636-641. 